\title{
sciendo
}

DOI: 10.2478/jolace-2021-0005

\section{Distant learning as a way to meet challenges: teaching English for medical students}

\author{
Olga Pechinkina \& Tatiana Vepreva \\ Northern (Arctic) Federal University, Russian Federation \\ o.pechinkina@narfu.ru, t.vepreva@narfu.ru
}

\begin{abstract}
In 2020 the world encountered a new virus. Nobody could predict it but it happened. The boundaries between countries were closed, people were obliged to stay at home, schools and universities were shut and the education was transferred online. We have to admit that not all educational institutions were ready to switch to the online format of teaching in such a short period. However, in conditions when there are no possibilities for face-to-face teaching educators are forced to find the most efficient ways of teaching English. In this paper, the authors aim to investigate online resources able to compensate for the lack of face-to-face communication. While doing research critical analysis of existing literature and generalisation of teaching experience were used. The findings revealed that even in distant learning particular resources can recompense for the absence of offline learning.
\end{abstract}

Keywords: online teaching, the English language, medicine, internet resources

\section{Introduction}

The contemporary world has faced the necessity to study online due to several factors such as globalisation, human migration, information transformation in society, increased competition in the economy, the role of information communication technologies (Avota, 2018), and, particularly, pandemic. The latter was a real challenge for university teachers even for those who deliver blended courses. Teaching and learning English require teacher-student and student-student communication in order to be successful. But in the case of distant learning face-to-face communication disappears although teaching all language skills (reading, writing, listening, and speaking) remains. Such a case entails a quick modification of teaching methods, approaches, and means while the content of the course should be fixed corresponding to the Federal State Standards of Higher Education. This transformation touches upon all educational programmes but the focus of the given article is directed at medical students. Thus, the aim of the research is to elaborate the available internet resources appropriate for the English for Medical Purposes course (EMP) and define the most effective ones to replace teacher-student or student-student face-to-face communication. To achieve the goal several objectives are to be realised: a) to scrutinise the latest Federal State Standards of Higher Education, b) to study existing courses of English for Medical Purposes, c) to analyse the available internet resources, and d) to present free internet resources appropriate for distant learning of medical students. Very often first-year students do not know enough about resources that can help them facilitate learning English and they cannot choose resources apposite for their skills and needs. We hypothesise it is possible to choose a range of internet resources that will replace face-to-face communication as much as possible. The significance of the research is to show the possibilities of distant learning for medical students to do the course of English efficiently. The course of English is chosen as the English language is considered to be an international language, so-called lingua franca, that facilitates further educational 
and professional development, international communication, science, academia, and the internet (Abugohar et al., 2019; Džuganová, 2019; Lodhi et al., 2018; Yang et al., 2019).

\section{Materials and methods}

In our research we undertook the following steps: studying the Federal State Standards of Higher Education, analysing the aims and content of English for Medical Purposes existing courses, and describing the internet resources apposite for medical students.

To study the official documents and educational programmes we used literature review and applied the method of critical analysis. To find the appropriate medical resources, we surfed the Internet and evaluated the found sources checking them for authorship, intended audience, purpose and currency. In addition, we generalised our own teaching experience.

\section{Discussion}

Worldwide English for Medical Purposes is taught from the point of view of real situations and it means that teaching English is focused on a particular context and specific vocabulary. But what is more important teaching Medical English relies on developing communication skills, problem-solving, and decision making (Milosavljevic et al., 2015). Upon completing the course, students are to be able to understand referent texts about the latest developments in their field, practice and improve speaking skills as well as writing ones, write research papers, and participate in student exchange and international scientific events. According to Antić (2015), students should master functional language (standard phrases for talking to patients, consulting, advising, writing emails, etc.), language skills (listening skill, fluency, etc.), and language systems (pronunciation for giving presentations, modal verbs for being polite or expressing compassion, etc.).

The aims and content of EMP vary according to particular professional fields as every sphere (cardiology, dentistry, surgery, etc.) has its specificity. But any course of English for medical students starts with general content. For example, in Japan (Rodis et al., 2014) the core curriculum for Dental English is aimed at responding to the ever-changing needs of the profession and includes two modules, one of which is offered at the pre-dental years and the second one at any other of the dental years. The course embraces basic and advanced terminology (including etymology and principles of terminology) and conversation (including dentist-patient and inter-professional communication). After completing the course, students will be able: a) to produce and perceive basic dental phrases, to comprehend their patients' speech, to inquire their patients about their medical and dental conditions, to explain some dental procedures, to access and use the information for native speakers published on the internet, for example, while looking for and applying for international dental conferences or journals (after the basic course), and b) to understand and respond to technical dental phrases, to create and deliver oral presentations on the specific dental topics, to communicate with health professionals via different forms (after the advanced course).

Another aspect of communication is the interaction with colleagues and professionals. So, students should acquire skills indispensable for meeting, interacting, and collaborating with peers.

To practice applied conversation, role play is one of the means. But it requires some preparatory work from the part of the teacher as a number of case scenarios should be prepared beforehand. Within the framework of distant learning, role-play can be organised within the academic groups or with other groups. Different situations can be 
performed such as self-introduction interaction, telephone inquiry, interviewing patients, medical history taking, scheduling patients' visits, chair-side conflict situations, etc.

As the future work supposes the doctor-patient interaction, students should be given specific tasks to be completed in pairs or groups. In such a way they learn to ask and answer questions on various topics, to formulate and express their thoughts, to overcome unease while speaking in public (Rodis et al., 2014). Moreover, such interaction involves casual and formal situations, discussions, facial expressions, gesturing, and sometimes culture studies as well.

In Finland the English syllabus consists of three courses: a) the course aimed at developing confidence, fluency, productive skills, and medical vocabulary, b) the course focused on practical writing skills, and c) the course oriented on multicultural patient interaction (Wallinheimo, Pitkänen, 2016, p.79). Students read materials, watch videos, complete exercises, search for additional information, give presentations, discuss questions, etc. The focus is on interaction because the future profession implies communication and context-specific activity. The course itself is widely based on taskbased language teaching as "learning is most effective when it is embedded in authentic tasks that are anchored in everyday contexts" (Hung et al. cited in Wallinheimo, Pitkänen, 2016, p.83). All the materials are provided on Moodle, the electronic learning platform. Usually, the class includes pre-session activities (to read materials, watch videos, prepare presentations, draft writing assignments), in-class activities (to solve task-based problem, report and discuss, analyse and assess, use text, video, audio materials, give peer feedback, write summaries, reviews, etc.), and post-session activities (to participate in forum discussions and chats, fulfill self-reflection, consult with a teacher). For instance, several groups are to elaborate a strategy for eliminating malaria in some remote village. Completing the task, students work with a wide range of materials, divide materials and responsibilities among themselves trying to find a feasible solution to the problem. Finally, they select the best approach after discussing the suggested variants (Wallinheimo, Pitkänen, 2016).

Mungra mentions the syllabus consisting of four modules: 1) acquiring high-frequency vocabulary and discrete linguistic forms, 2) improving reading comprehension strategies, 3) analysing academic genres common to a specific discipline, and 4) completing authentic criterion tasks (Mungra, 2010, p.153). The course is aimed at teaching students to write scientific abstracts in English moving from a particular clinical case to an in-depth understanding of how research works for the specific practical question.

In Pakistan, the course of English for Medical Purposes relies on problem-based and content-based learning (Lodhi et al., 2018). To create real-life situations to practice communication, researchers suggest using information and communication technologies. But there is still place for medical terminology teaching and grammar translation method. As for a lesson format, it has a twofold structure: the first lesson focuses on vocabulary presentation and acquisition whereas the second one - on applying new material in the context that can be filling in hospital forms and papers, using some medical equipment, exploration of treatments, writing emails, discussing medical experience and others (Antić, 2015; Lodhi et al., 2018).

Conceptually the problem-based method can be called "problem-first learning" (Yalcin et al., 2006) as it is based on cases raised by a specific problem with subsequent investigation of underlying concepts and principles. This method has both advantages (enhancing understanding of the matter, improving collaboration between disciplines, increasing the knowledge retention and motivation of both students and teachers) and disadvantages (excessive demands on staff time, set-up and maintenance costs, increased 
stress for both students and staff) (Yalcin et al., 2006). But in the situation of distant learning problem-based method is one of the options to be used via such communication platforms as Microsoft Teams or Zoom. Working in small groups activates some psychotherapeutic principles (listening and tolerating hostility), promotes democratic process when group members work together, determine the rules, take initiative, share knowledge, and show mutual respect.

One of the options of the problem-based method is medical case studies (Antić, 2015). In medicine, it is a central diagnostic method as it aims at a patient and his problem. In the framework of EMP, case study allows learners to revise grammar, ask and answer questions, improve word formation, practice communication skills, prepare presentations, write research papers, develop team-working skills, and so on.

Although many researchers insist on enhancing communicative skills there is still an opinion that two main skills of speaking are fluency and accuracy (Abugohar et al., p.212). They should not be neglected either by teachers or students.

Writing is a part of the job that is why writing assignments should be paid special attention to. Researchers (Lum et al, 2018, p.9) distinguish thirteen writing genres in medical studies serving two purposes: a) enhancing reflective thinking (for example, self and peer evaluations) and b) essay/report writing (reports, annotated bibliographies, research proposals, field notes, etc.). These genres have three levels of difficulty: a) care plans and portfolios, b) discharge summaries and dissertation proposals, and c) argumentative essays and dissertations. Although earlier 29 types were found in medical schools in the United States, the key genres are considered to be patient's history, physical examination reports, progress reports, discharge summaries, clinical or laboratory research, and grant proposals. Thus, medical writing takes a significant place in EMP.

The stages to develop and enhance academic writing skills can be as follows (Mungra, 2010, p.154): a) read a clinical case with focus on lexis, form, and academic register, b) learn how to deal with a patient to get clinically relevant information, formulate clinical questions about possible therapeutic options, and interrogate a medical database, c) find research publications and research abstracts corresponding to the clinical case in databases and online libraries, d) analyse the academic publication to identify the logic of an author following the IMRaD format, e) highlight and structure characteristics of various research designs, f) consider a series of abstracts to understand different abstracts' types and varied methodological research designs, g) to assess the text of the article for linguistic features such as academic register, syntax and semantics, readerwriter interaction, lexico-grammatical choices and others, h) read an abstract with a removed method section, reconstruct this section relying on the rest of the abstract and write this missing section.

Listening comprehension is especially important for medical students as their future job presupposes understanding patients' complaints and descriptions of their health states or results of laboratory tests communicated via telephone as well as participating in international conferences (Džuganová, 2019). According to B. Džuganová (Džuganová, 2019), videos with captions are one of the most appropriate possibilities to train listening comprehension as they combine video, sound, and text. Captioned professional medical videos give students the possibility to perceive authentic medical language and authentic situations along with improving language proficiency. The didactic work with videos (the length of which is from two to five minutes) consists of four activities: Lead-in, Reading comprehensions, Watching a video, and Conversation. 
Researchers from Japan (Rodis et al., 2014) assert that special attention should be paid to teaching terminology. Students should focus on the overall meaning of the term, learn it in context, and be ready to rephrase their statements. Term pronunciation is also important and can be improved with the use of pronunciation guides, audio/video clips, and slideshow presentations. This opinion is supported by the Taiwanese researcher who claims that "If a person does not understand grammar, he may be able to express a little thought in words, but if there is no word, no meaning can be expressed" (Liu, 2019, p.1187) and suggests using a corpus in medical English vocabulary teaching. As there are numerous sub-types of the corpus (for instance, nursing English corpus, neurosurgery English corpus, abstract corpus of medical papers, etc.) they can be used in various professional medical spheres to meet the needs and requirements of a particular educational programme. Corpus-based teaching allows building a medical terminology frequency table apposite for the specific profile and consists of four levels: reading and writing, identifying meaning, understanding in a specific context, and using in different communicative situations (Liu, 2019).

So, there is a variety of syllabuses and methods of teaching medical English offered by researchers. We should choose those that meet the challenges in current situation.

\section{Results}

The system of Russian higher education is determined by the Federal State Standards of Higher Education. According to the standards, a student upon graduation should possess a number of competences with regard to English or another foreign language. Four most popular medical programmes are chosen for our research. They are General Medicine, Paediatrics, Dentistry, and Pharmacy. Future pharmacists have to develop Universal Communication Competence which means to be able to implement modern communicative technologies in foreign languages in academic and professional interaction. As for General Medicine, Paediatrics, and Dentistry programmes, new Federal State Standards of Higher Education are currently presented for discussion (Portal..., 2020). Along with these documents, all the students form Universal Communication Competence and must be able to realise oral and written business communication in Russian and foreign languages. In addition to this competence future dentists should also form General Professional Competence which presupposes readiness for oral and written communication in Russian and foreign languages to solve professional problems.

To illustrate how these standards are realised, we analysed various syllabuses of English for Medical Purposes. At Northern State Medical University (Arkhangelsk, Russia), for example, students of Dentistry, General Medicine and Paediatrics programmes are taught Foreign Language in the first semester. The aim of this discipline is to acquire the basics of oral and written forms of communication necessary for professional development and their use as a means of communication. In the second semester, future doctors and pediatricians study Basics of Professional Activity in a Foreign Language. This discipline aims at building up the vocabulary for professional sphere and developing skills for occupational activity and self-development. As for future dentists, they are offered an elective course connected with the translation of medical texts to master skills in understanding written sources. Students of the Pharmacy programme learn English for three semesters trying to obtain oral and written forms of communication to use them as a means of communication and self-development.

In Northern State Medical University, distant learning is realised via Moodle (Modular Object-Oriented Dynamic Learning Environment). The English lecturers used to employ it for blended learning but at the beginning of the pandemic, it became the first online 
platform to continue the process of education. Moodle contains a variety of activities and resources which can enrich and facilitate the learning process. On the first page of the course, there is all necessary information such as the title, annotation, contents, the name of the lecturer(s), news forum, and literature. Topics are grouped into sections combining theoretical and practical materials. Such an organisation of the material turns out to be very convenient as a student can clearly see all the work ahead in one place.

The core course content is concentrated in such sections as the Lesson module, the Assignment activity, and the Quiz. The Lesson module is organised by an alternation of theoretical material with choice questions checking the comprehension. Providing a student answer is correct, $\mathrm{s} /$ he goes to the next page of the lesson, if not, stays on the same page and is advised to reread the information. The Assignment activity allows giving tasks that students submit for the teacher's assessment. The fulfilled tasks can be done in different formats, typed into Moodle, or uploaded in files. It is also possible to record the task in audio or video files for the lecturer to listen and see the learner. There is a possibility for a teacher to set deadlines, which motivates the students to do everything in time. The Quiz section enables the lecturer to create a great number of various types of tests. Among them, there are Multiple Choice, True/False, Missing Word, Matching, Short Answer, Drag and Drop into Text, Gap Fill, and others. The questions of the tests are kept in one database, are easily combined, and may be exported or imported to one or another course. The aim of the tests may be educative demonstrating the correct answers and explanations at the end, or control one, providing only the grade.

Moodle presents a set of tools for collaborative work. To train students for peer assessment the lecturer may use Workshop activity. Here the students submit their own works typed into Moodle's editor or uploaded in files of any type and are given some other works for the peer-review. As a rule, beforehand they are provided with a template of assessment and at the end of the activity, the lecturer demonstrates the final score and best examples. This activity helps learners not only understand their language use better but define the strength and weaknesses of their performance.

Medical students have to acquire many specialised words and terms and the Glossary module becomes a valuable tool for the joint work of the participants of the course. The lecturer may start creating the glossary giving students the opportunity to add new words they encounter afterward. Filling unfamiliar words with definitions can encourage learning, better remembering, and using new terms in context.

The Wiki module is essential for students' group work. The whole group or a limited number of people can create and edit a joint project. The students easily develop content just searching for, discussing, and adding the necessary information. Collaborating on one document they learn how to do teamwork.

All the above-mentioned activities have been widely used in blended learning and are of no novelty to the majority of lecturers. But in an unprecedented situation when there is no opportunity to conduct face-to-face teaching, we regard the communicative block of Moodle as of paramount importance. Let us consider those that are used in Northern State Medical University and can at least partially substitute face-to-face communication in one or another way.

The Forum module allows exchanging ideas by posting comments in asynchronous discussion. Usually, students type the questions they want to get an answer for and receive feedback sometime later. The lecturer can facilitate discussion of necessary problems by posting a particular question and asking everybody to express his/her opinion. Such discussions help the lecturer control the level of students' comprehension and find gaps in their knowledge. 
The Chat module is vital as it allows a real-time synchronous discussion. Students change text messages and get replies immediately. The Chat is open for discussion in the time of the lesson according to the timetable. Learners can ask their lecturer any questions and receive competent answers. It is also a place where students can quickly distribute tasks, or discuss urgent problems.

The true treasure in Moodle is the BigBlueButton activity module that allows the creation of a virtual meeting room for real-time communication. The lecturer has an opportunity to see all the students and contact them. As a rule, the lecturer explains new topic for 10-15 minutes, providing it with illustrative material (presentations, photographs, films, etc.), and invites students to participate in the discussion through a group chat. The participants of the conference have a choice either to listen or to speak during the session. Web conferences in Moodle greatly enrich the educational process as they make it more interesting and accessible to students.

Besides virtual learning environments, there is a great variety of other internet applications and gadgets to benefit the process of language acquisition.

WhatsApp is an application that can facilitate student-student and teacher-student communication. It is considered to be "an aid of communication and a tool of circulating educational resources and information to students" (Asgari Arani, 2017, p.99). The application has several advantages such as a low cost, the ability to send numerous messages, immediacy, the ability to maintain a dialogue with a large number of people synchronously, the feeling of togetherness, and others. During the research short complementary lessons were sent to the students of the experimental group three times a week, though control group students had traditional classes. The tasks were aimed at word morphology and terminology, paraphrasing and sentence writing, oral presentation issues like note-taking and listening tactics. The survey showed the students from the former group were more enthusiastic and learned more than their peers from the conventional group. Moreover, the experimental group students managed to cope with class stress, strengthen self-confidence, and devote class time to more complicated points.

Researchers from Finland are proponents of iPads ensuring access to the web, email, books, medical videos, and computer games that can be used for studying medicine practically everywhere (Wallinheimo, Pitkänen, 2016, p.78). Students use iPads for consulting a dictionary, watching videos, listening, reading electronic newspapers, magazines and journals, communicating in social media, using language apps, storing course materials, scheduling, preparing and presenting data and presentations, etc. Whatever device students use there are audio and video resources with a medical focus that can be accessed anytime, for example, TEDMED - http://www.tedmed.com/ and MEDtube - https:// medtube.net.

Not only video services are used by medical students. Social media (YouTube, Facebook, and Twitter being the most frequently used) have become an important resource for medical communities that can teach, engage, connect and provide accurate and credible health information (Sutherland, Jalali, 2017). Moreover, medical society can disseminate conference announcements and content via social media making innovations and discoveries available for those who are interested in the topic.

Another online resource available for everyone having access to the internet is Wikipedia. Quite often educators are rather skeptical about the use of Wikipedia as an information source in the educational process as there is no strict editorial review but different levels of the expertise of the contributors. Studies show that Wikipedia is widely used by undergraduate medical students, junior physicians, and practitioners (Kräenbring et al., 2014). Meanwhile, the researchers compared the accuracy and 
completeness of drug information in English language Wikipedia and standard textbooks of pharmacology (Kräenbring et al., 2014). The results obtained (100 drugs analysed from the list of 300 curricular drugs) showed few factual errors and high practicality of curricular drug information for undergraduate teaching. Thus, Wikipedia as well as, for example, the online database Medscape drug reference (https://reference.medscape.com/drugs) are an accurate and informative source of drug information for undergraduate medical students who can not only get information there but participate in editing.

The examples of eLearning resources for neurosurgical training (Stienen et al., 2016) are eBrain, AIIMS NETS, and SCI eLearning. eBrain is a project available for students and educators worldwide. It includes over 650 interactive lessons in 25 modules incorporating webinars, virtual case reports, assessments, learning paths, and bibliographies in the form of text, images, video, and audio content. AIIMS NETS is a free of charge web-based resource that provides virtual education material in the form of videos, webinars, and tele-education material in the spheres of anatomy, pharmacology, pathology, radiology, neurology, and surgical techniques. SCI eLearning is a web-based resource containing training materials for physicians, nurses, physiotherapists, and social workers. The resource provides topical webinars and offers references for further reading.

Slideshow presentations can be widely used for group and individual work as they can ensure better understanding and remembering new vocabulary, construction, or topic. Added subtitles in English or interpretation/translation of some terms will clarify the content. The use of model cast photos or 3D modeling will enhance the learner's cognitive learning due to visual input (Rodis et al., 2014).

For mastering vocabulary, it is crucial not only to remember a new term but also to use it further in oral or written form. Innerbody Research site (https://www.innerbody.com) is a health resource written by specialists in Medicine and reviewed by medical experts. Students can visualise human anatomy systems and read the information about them practicing acquired terms.

Free Anatomy Quiz (https://www.free-anatomy-quiz.com) is one more website for future doctors. It aims to help students of health-related disciplines learn and practise Anatomy, Physiology, and Therapy. The resource offers a great number of quizzes on these topics. Medical English consists of terms derived from Greek and Latin, so there are also quizzes on common roots, suffixes, and prefixes. An advantage of this website is the rubric with short articles for reading with questions to check comprehension. Besides, teachers can find images, crosswords, and worksheets possible for printing out and using as handouts.

As for delivery, teaching methods include face-to-face learning or blended learning. In our research, we focus on the blended learning with a special emphasis on the technologies and resources of the distant learning that can be called open studies, estudies, online learning, and virtual studies (Avota, 2018). Undoubtedly distant learning has some factors challenging its use (for instance, access to online resources, information literacy of a teacher and students, internet connection, etc.) (Rodis et al., 2014), availability of a computer, tablet, or smartphone for some social groups, fatigue from screen staring, presence of constant motivation and self-control, and privacy issue (as patient's photos or videos can be used) (Stienen et al., 2016). But the advantages of distant learning in some circumstances can outweigh the disadvantages: a) content can be delivered via computer, smartphone, text, audio, video or graphic files, numerous online databases and websites, b) distant learning can be self-paced or teacher-led, c) it can teach 
and monitor or control, d) content can be available for students during the whole semester or set for a due deadline, e) print-outs of upcoming classes can be available for students in advance for their convenience (Rodis et al., 2014), f) it can train all language skills namely reading, writing, listening and speaking, g) resources can be chosen according to the language proficiency of a particular student, and others.

\section{Conclusion}

To sum up, we have found that contemporary information and communication technologies offer a wide range of resources and software easing the educational process. We claim online learning cannot replace lecturers completely. Still, there are tools and programmes able to facilitate teaching and learning English in lockdown measures. We propose to use one virtual educational platform (Moodle) and complement it with the necessary additions because together they involve all language activities, and allow competent communication. As a rule, internet programmes, gadgets, applications are familiar to students and do not put an additional strain on them. Synchronous and asynchronous formats make it possible for learners to work in groups and individually which is similar to class (offline) learning.

We hope the study will be a useful aid for teachers of English from medical institutions. To further our research we plan to create a new syllabus of English for Medical Purposes that meets the requirements of the time. One more future perspective to be researched is mLearning (mobile learning) mediated by a compact digital portable device that is always present at his owner. This research is very promising as the number of holders of such gadgets is constantly growing.

\section{References}

Abugohar, M. A., Al-Hnifat, M. A., Al-Smadi, O. A., Rashid, R. A., Yunus, K. (2019). English language speaking skill issues in an EMP context: causes and solutions. International Journal of English Linguistics, 9 (3), 211-225. DOI:10.5539/IJEL.V9N3P211

Antić, Z. (2015). Benefits of student-centered tandem teaching in medical English. Language of Medicine, 143(7-8), 500-504. DOI: 10.2298/SARH1508500A

Asgari Arani, J. (2017). An innovative media platform-supported blended methodology in English for dental purposes program. International Journal of Emerging Technologies in Learning (iJET), 12(3), 98-109. DOI.org/10.3991/ijet.v12i03.6441

Avota, B. (2018). Evaluation of readiness for the professional development of medical practitioners in terms of distance learning. Rural Environment. Education. Personality, 11, 331-338. DOI: 10.22616/REEP.2018.040

Džuganová, B. (2019). Teaching medical English through professional captioning videos. Journal of Language and Cultural Education, 7, 95-107. DOI: 10.2478/jolace2019-0013

Kräenbring, J., Penza, T. M., Gutmann, J., Muehlich, S., Zolk, O., Wojnowski, L., Maas, R., Engelhardt, S., Sarikas, A. (2014). Accuracy and completeness of drug information in Wikipedia: a comparison with standard textbooks of pharmacology. PLoS One, 9(9), e106930. DOI: 10.1371/journal.pone.0106930

Krishnasamy, Ch., Sik Yin Ong, Yock, Y., Lim, I. S. Sh., Rees, R., Car, J. (2016). Factors influencing the implementation, adoption, use, sustainability, and scalability of mLearning for medical and nursing education: a systematic review protocol. Systematic Reviews, 5, 178. DOI:10.1186/s13643-016-0354-X 
Liu, Ch. (2019). Approach of the corpus research on medical English prepositions. 2019 International Conference on Arts, Management, Education, and Innovation, (ICAMEI 2019), 1187-1191. DOI:10.23977/icamei.2019.244

Lodhi, M. A., Shamim, M., Robab, M., Shahzad, S. H., Ashraf, A. (2018). English for doctors: an ESP approach to needs analysis and course design for medical students. International Journal of English Linguistics, 8, 205-214. DOI:10.5539/ijel.v8n5p205

Lum, L., Alqazli, M., Englander, K. (2018). Academic literacy requirements of health professions programs: challenges for ESL students. TESL Canada Journal, 35(1), 1-28. DOI: $10.18806 /$ tesl.v35i1.1282

Milosavljevic, N. D., Vuletić, A., Jovković, L. (2015). Learning medical English: a prerequisite for successful academic and professional education. Srpski arhiv za celokupno lekarstvo, 143(3-4), 237-240. DOI: 10.2298/SARH1504237M

Mungra, Ph. (2010). Teaching writing of scientific abstracts in English: CLIL methodology in an integrated English and Medicine course. Ibérica, 20, 151-165.

Portal Federal'nyh gosudarstvennyh obrazovatel'nyh standartov vysshego obrazovaniya [Portal of Federal State Educational Standards of Higher Education] Portal Federal'nyh gosudarstvennyh obrazovatel'nyh standartov vysshego obrazovaniya =Portal of federal state educational standards of higher education. Available on: http://fgosvo.ru/fgosvo/143/141/17/76

Rodis, O. M. M., Barroga, E., Barron, J. P. et al. (2014). A proposed core curriculum for dental English education in Japan. BMC Medical Education, 14(1), 239. DOI: $10.1186 / \mathrm{s} 12909-014-0239-4$

Stienen, M., Schaller, K., Cock, H. R. et al. (2016). eLearning resources to supplement postgraduate neurosurgery training. Acta Neurochirurgica, 159, 325-337. DOI: 10.1007/s00701-016-3042-7

Sutherland, S., Jalali, A. (2017). Social media as an open-learning resource in medical education: current perspectives. Advances in Medical Education and Practice, 8, 369 375. DOI: $10.2147 /$ AMEP.S112594

Wallinheimo, K., Pitkänen, K. K. (2016). iPads in medical language courses at the University of Helsinki. Language Learning in Higher Education, 6(1), 77-94. DOI 10.1515/cercles-2016-0004

Yalcin, B. M., Karahan, T. F., Karadenizli, D., Sahin, E. M. (2006). Short-term effects of problem-based learning curriculum on students' self-directed skills development. Croatian Medical Journal, 47(3), 491-498.

Yang, M., O'Sullivan, P. S., Irby, D. M. et al. (2019). Challenges and adaptations in implementing an English-medium medical program: a case study in China. $B M C$ Medical Education, 19(15). DOI: 10.1186/s12909-018-1452-3

\section{Contact:}

Dr. Olga Pechinkina

Northern (Arctic) Federal University

Dept. of English Philology Nordic languages and Language Pedagogy

Arkhangel'sk

Russian Federation

o.pechinkina@narfu.ru

t.vepreva@narfu.ru 